High Temperature Materials and Processes, VoL 10, No. 1, 1991

\title{
Intermetallic Matrix Reinforcement Ceramic Fibers by Chemical Vapor Deposition
}

\author{
V. Revankar and V. Hlavacek \\ Ceramic and Reaction Engineering, Laboratory, State University of New York at Buffalo, \\ Buffalo, New York 14260, USA

\section{CONTENTS}

\section{Page}

$\begin{array}{lr}\text { ABSTRACT } & 44 \\ \text { 1. TECHNICAL BACKGROUND } & 44 \\ \text { 2. EXPERIMENTAL PROCEDURE } & 44 \\ \text { 3. RESULTS AND DISCUSSION } & 45 \\ \text { 3.1. Titanium Diboride Fiber } & 45 \\ \text { 3.2. Boron Carbide and Titanium Carbide } \\ \text { Fibers } & 50 \\ \text { 4. SUMMARY } & 50 \\ \text { 5. CONCLUSIONS } & 54 \\ \text { ACKNOWLEDGEMENTS } & 54 \\ \text { REFERENCES } & 54\end{array}$




\begin{abstract}
Titanium diboride, titanium carbide, boron carbide and other fibers have been developed in our laboratory for possible use in the intermetallic matrix reinforcement. Our paper highlights a process condition required for the development of these fibers with 100-200 $\mu \mathrm{m}$ diameter on different core substrate. These fibers exhibited good mechanical and physical properties which are discussed briefly. The method for improving the physical and mechanical properties is also explained. Effect of different reactants on deposition rate and deposit morphology has been discussed.
\end{abstract}

\section{TECHNICAL BACKGROUND}

A new generation of composite materials is revolutionizing today's aircraft and automotive industries $/ 1 /$. In these high technology applications, weight, strength, and stiffness are critical parameters which can be achieved by using high-performance ceramic material composites $12 \%$. These ceramic materials offer many outstanding properties for hightemperature applications. This attention led to the discovery of fibers which have excellent hightemperature strength and corrosion resistance, good thermal shock resistance, low density, and low coefficient of thermal expansion. High-performance fibers are available only at high prices and, as a result, tend to serve specialized and restricted markets. Basically, three factors affect this price: raw material, manufacturing, and more importantly new market development cost. Secondly, the use is partly limited because of their brittle nature and large degree of scatter in strengths which often lead to catastrophic failure. A number of techniques have been considered to lessen or eliminate these problems $/ 3 /$.

Over the past few years, numerous patents and publications have revealed the use of simple organometallic compounds, metal halides, and polymer precursors for routes to ceramics fibers /4/. High Gibb's free energy of formation or organometallic compound frequently allows for lower temperature of formation of ceramics. This fact is utilized in the CVD process. The volatile organometallic precursors allow for simple purification by superfractionalization so that CVD process results in an ultra-clean material. Very recent experimental observations predict that traces of impurities in a fiber (e.g., calcium) result in a fast hightemperature degradation $/ 5 /$.

The achievement of consistently high fiber strengths over a long length is important for successful implementation in many composite systems. This requires highly controlled processing operation and conditions $16 \%$. Coating defects may also induce some kind of flaws or microbending losses in the fiber $17,8 \%$. Only two ceramic fibers are available commercially (boron and silicon carbide), but these fibers do not match the properties required for the advanced composite system. For the intermetallic matrix reinforcement we are looking for a special kind of fiber. Metal matrix composites offer low weight, high strength, high stiffness, and high temperature capabilities to satisfy the performance requirements of future advanced aerospace systems. By choosing a matrix material that bonds well to the fiber, is ductile, and stands up to the environment, properties of the composite can be tailored to the needs of advanced power and propulsion systems. Titanium diboride, titanium carbide, and boron carbide fiber compositions are proposed as reinforcement material for intermetallic matrices in this paper.

Though the CVD of $\mathrm{TiB}_{2}$ has been carried out on various substrates of different shapes, very little work has been done on fibers $14,9,10 \%$. Even though $\mathrm{TiB}_{2}$ exhibits very good oxidation resistance, the technological difficulties experienced in manufacturing of this fiber have so far prevented it from being used on a large scale. There is very little information available on $\mathrm{CVD}$ of $\mathrm{TiC}$ and $\mathrm{B}_{4} \mathrm{C}$ fibers.

\section{EXPERIMENTAL PROCEDURE}

Reagent grade boron trichloride, methane, and carbon tetrachloride chemicals were used without further purification. Argon and hydrogen were purified by passing it first through active copper nets heated above $400^{\circ} \mathrm{C}$ and then through the series of drying towers. The final oxygen content in the gases was less than 1 PPM. Reagent grade titanium tetrachloride was redistilled again to reduce the impurities. The final composition of impurities in titanium tetrachloride in $\mathrm{PPM}$ is $\mathrm{Fe}<10, \mathrm{Si} \simeq 50, \mathrm{Sn} \simeq 100, \mathrm{C} \simeq 50, \mathrm{~V} \simeq 10$.

Different substrate materials were used to find out the suitability in deposition (C, W, MO, and Ti). The substrate material was prepared by cleaning the surface 
with different methods: (1) steaming the substrate around $200^{\circ} \mathrm{C}$ for $5 \mathrm{~min}$.; (2) heated to $400^{\circ} \mathrm{C}$ by passing hydrogen for $3 \mathrm{~min}$; (3) boiling the substrate with $\mathrm{HNO}_{3}$ acid for $8 \mathrm{~min}$. The nitric acid treatment gave the best result for the microcrystalline smooth deposit.

The equipment used in this study has been discussed elsewhere $/ 11 /$. The batch system consists of a quartz reactor with the electrode ports. A small diameter substrate wire runs through the electrodes, and suitable gases are introduced. The material is deposited on the resistively heated wire. In the continuous system filament to be coated enters the apparatus through a mercury seal and is heated in an inert gas atmosphere, leaving the apparatus through a similar arrangement at the exit end. The reacting gaseous mixture enters the reactor at different axial and angular positions to increase accessibility and uniformity of reactants on the filament surface. A motor driven reel draws the fiber through the apparatus at a steady controlled rate. The total system is shown in Fig. 1. The resultant fibers were analyzed by SEM, EPM, X-diffraction, and elemental analysis.

\section{RESULTS AND DISCUSSION}

The hydrogen reduction of halides process is an effective technique for the synthesis of ceramic fibers by CVD. The principle of this technique is as follows: Hydrogen saturated with metal halide $\left(\mathrm{TiCl}_{4}\right)$ or nonmetal halide $\left(\mathrm{CCl}_{4}, \mathrm{BCl}_{3}\right)$ or a mixture of these halides is passed into the reactor in which the base filament is heated resistively. The following fibers have been synthesized by using the above principle: $\mathrm{TiB}_{2}$, $\mathrm{TiC}$, and $\mathrm{B}_{4} \mathrm{C}$. Only $\mathrm{TiB}_{2}$ fiber was given extra attention because of its special interest and use.

\subsection{Titanium Diboride Fiber}

We tried two different ways to synthesize this fiber. The first approach was direct boriding of the titanium fiber. In this process boron was deposited on the titanium fibers by a $\mathrm{BCl}_{3}+\mathrm{H}_{2}$ reduction method, and whole material was subsequently heated to high temperature to allow the counter diffusion of boron and titanium. The resultant fiber (shown in Fig. 2) was irregular in shape

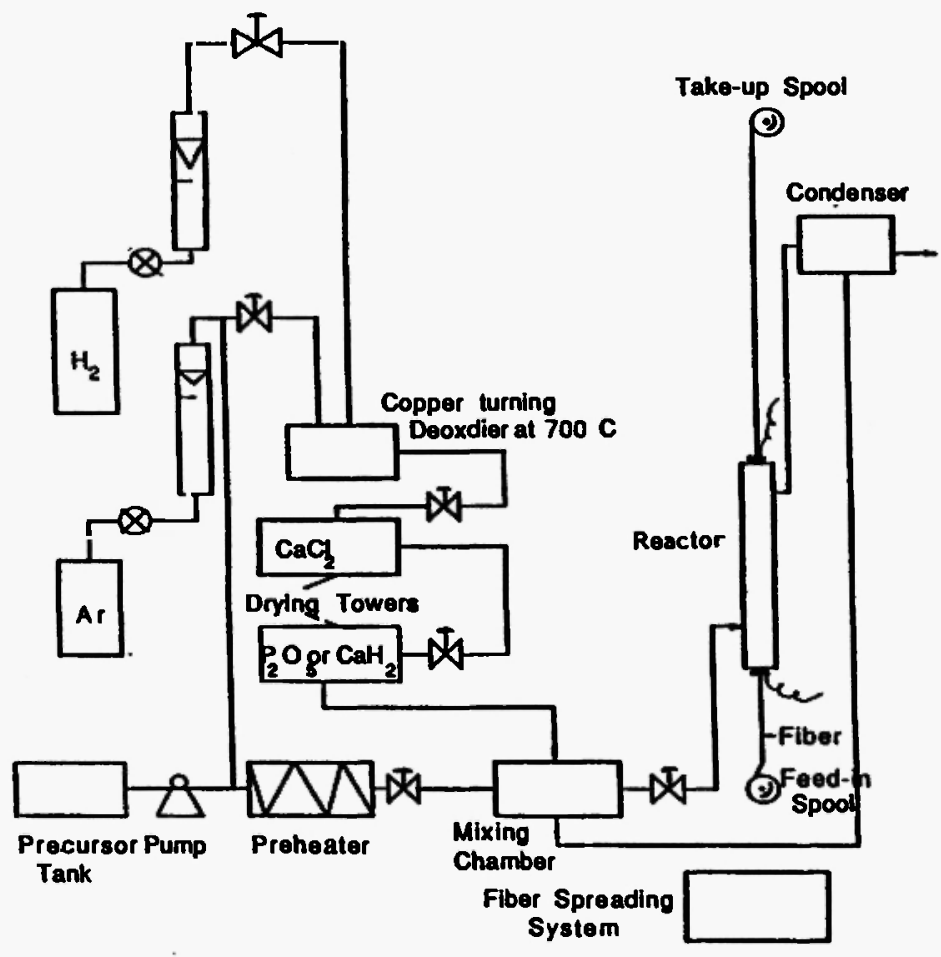

Fig. 1: CVD reactor flow diagram. 
and exhibited very low strength. This was due to the stresses produced by the operating conditions.

The second approach was a chemical vapor deposition route: Hydrogen reduction of mixed vaporized halide of boron and titanium.

$$
\begin{gathered}
2 \mathrm{BCl}_{3}+\mathrm{TiCl}_{4}+\mathrm{H}_{2} \text { (large excess) } \frac{\mathrm{Ar} \text { gas }}{1100-1400^{\circ} \mathrm{C}} \\
T i B_{2}+10 \mathrm{HCl}+\mathrm{H}_{2}
\end{gathered}
$$
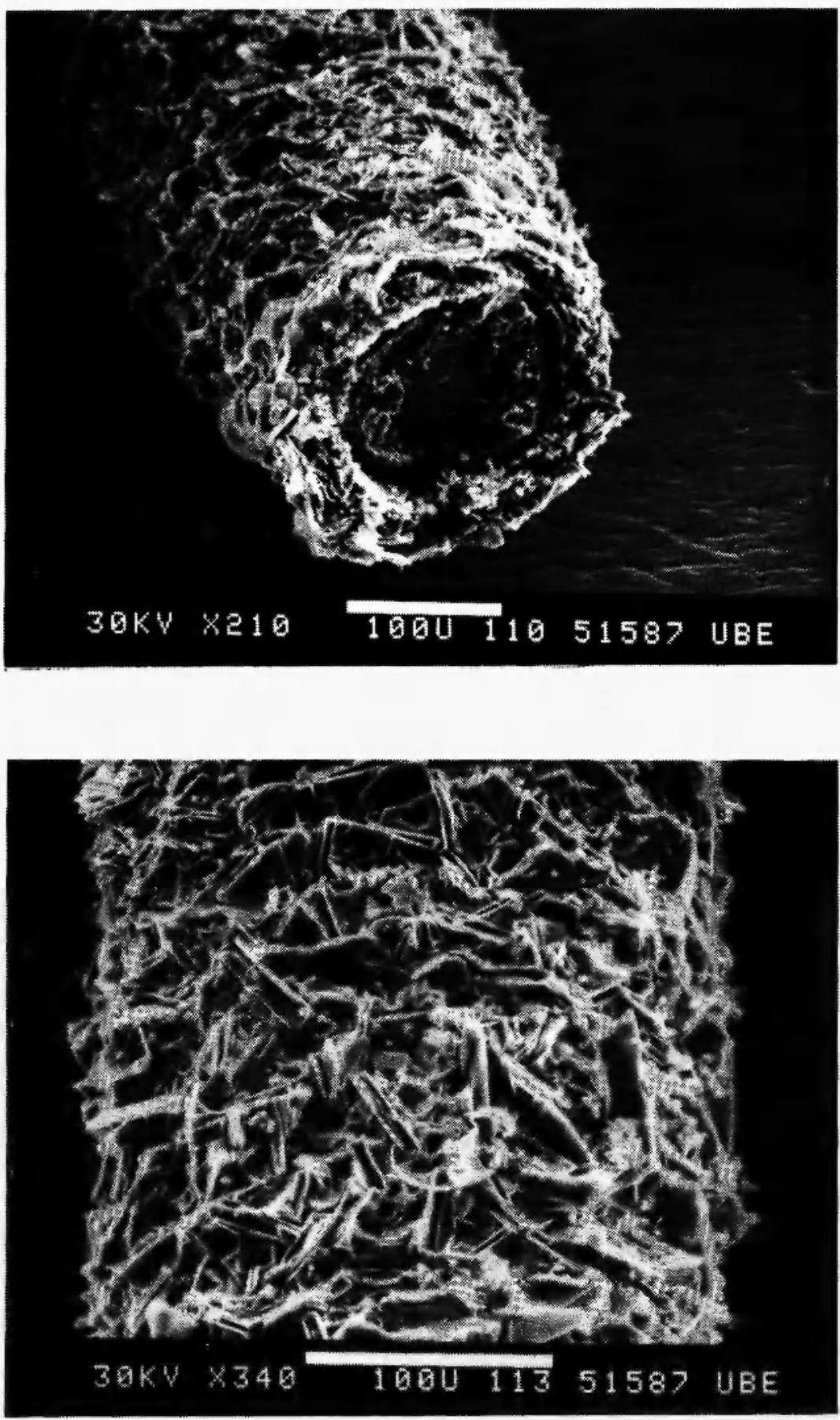

Fig. 2: Fiber produced from direct boriding. 
The core material is resistively heated, and deposition is carried out using extra pure reactants and gases. In this process the only thermodynamically possible condensed phases are $\mathrm{TiB}_{2}$ or $\mathrm{TiB}_{2}$ and $\mathrm{B}$ or just $\mathrm{B}$, as shown by Randich and Geilach /12/. Boron is deposited only at high boron to titanium ratios. Increasing the $\mathrm{Ti}$ to $\mathrm{CI}$ ratio increases the titanium diboride deposition, but it also increases the co-deposition of boron. Therefore, the B:Ti ratio was kept between 2.5-3. The $\mathrm{H}: \mathrm{Cl}$ value was kept above 7 . Low hydrogen to chlorine ratio in the system decreases the rate of formation of $\mathrm{TiB}_{2}$, and, in addition, many side products were observed for this low ratio (e.g., $\mathrm{TiCl}_{2}, \mathrm{TiCl}_{3}$, etc.). The resultant fiber is shown in Fig. 3 and possesses cracks on the surface. This is due to the stresses produced by a thermal expansion mismatch between the tungsten core and the $\mathrm{TiB}_{2}$ layer. The resultant strength is very low (of the order of 30-40 KSI). The value of the elastic modulus was around 10-15 MIS.

Our effort has been concentrated on reducing this thermal expansion mismatch effect, i.e., to reduce the brittleness of the fiber obtained by chemical vapor deposition on the tungsten core. Various methods were tried. First, a secondary soft pyrolytic carbon layer (spongy in nature) was deposited between the ceramic deposit and the core. This procedure gave very encouraging results. The pyrolytic soft carbon deposit was obtained at low temperature $\left(-900^{\circ} \mathrm{C}\right)$ using carbon tetrachloride, hydrogen, and argon. Carbon tetrachloride was preferred over methane gas because of better control of the properties and rate of soft carbon deposit. The fiber is shown in Fig. 4. This procedure reduced the brittleness dramatically and also enhanced the mechanical properties. The strength and carbon deposition effect is given in Fig. 5. Recently we tried a graded deposition method. A few microns of pure pyrolytic carbon layer was first deposited, followed by graded deposition of pure titanium diboride material. A thick pure $\mathrm{TiB}_{2}$ layer up to $80 \mu \mathrm{m}$ was obtained. The total thickness of the deposit was in the range of 40$150 \mu \mathrm{m}$.

The reaction producing $\mathrm{TiB}_{2}$ was studied at different flow rates and temperatures. The results are shown in Fig. 6. One can see from the figure that there is an optimum flow rate. However, deposition rate varies with temperature. One has to work at optimum temperature and supersaturation to get microcrystalline smooth deposits; higher temperature $\left(>1450^{\circ} \mathrm{C}\right)$ produced platelet kinds of deposits /13/ (see Fig. 7). The strength and modulus of the resultant fibers were

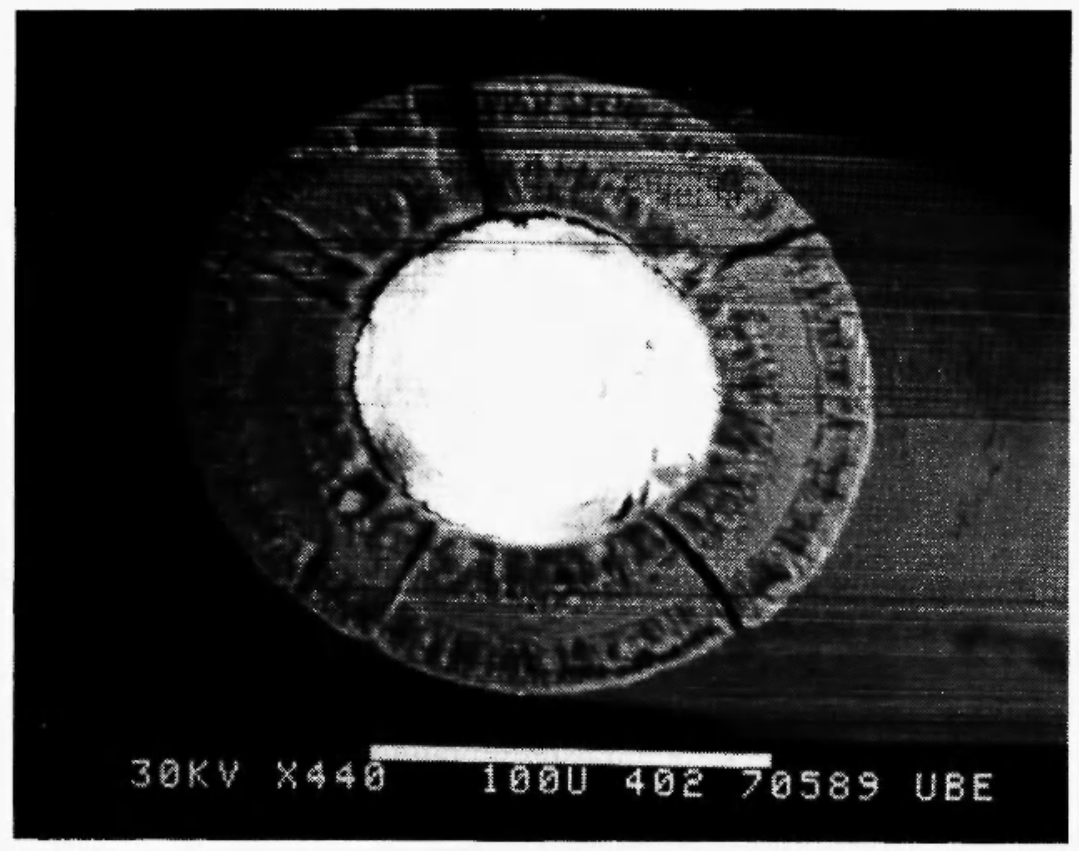

Fig. 3: $\mathrm{TiB}_{2}$ fiber without intermediate carbon layer. 


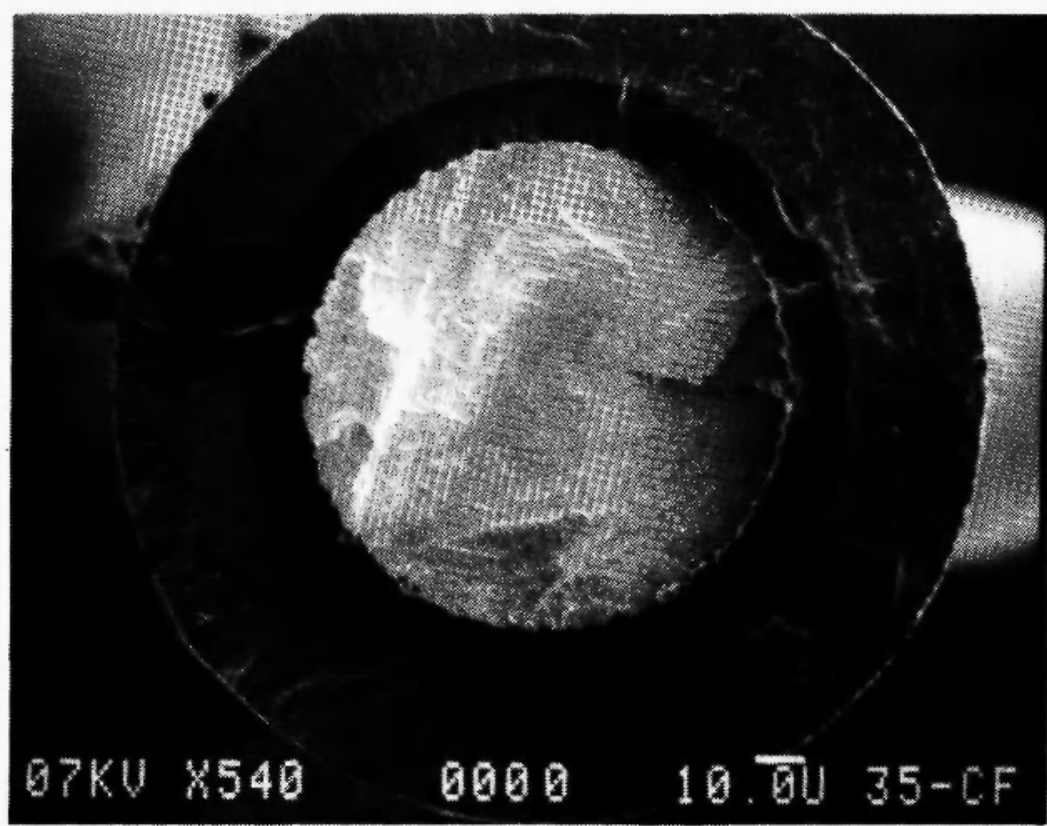

Fig. 4: $\mathrm{TiB}_{2}$ fiber with intermediate carbon layer.

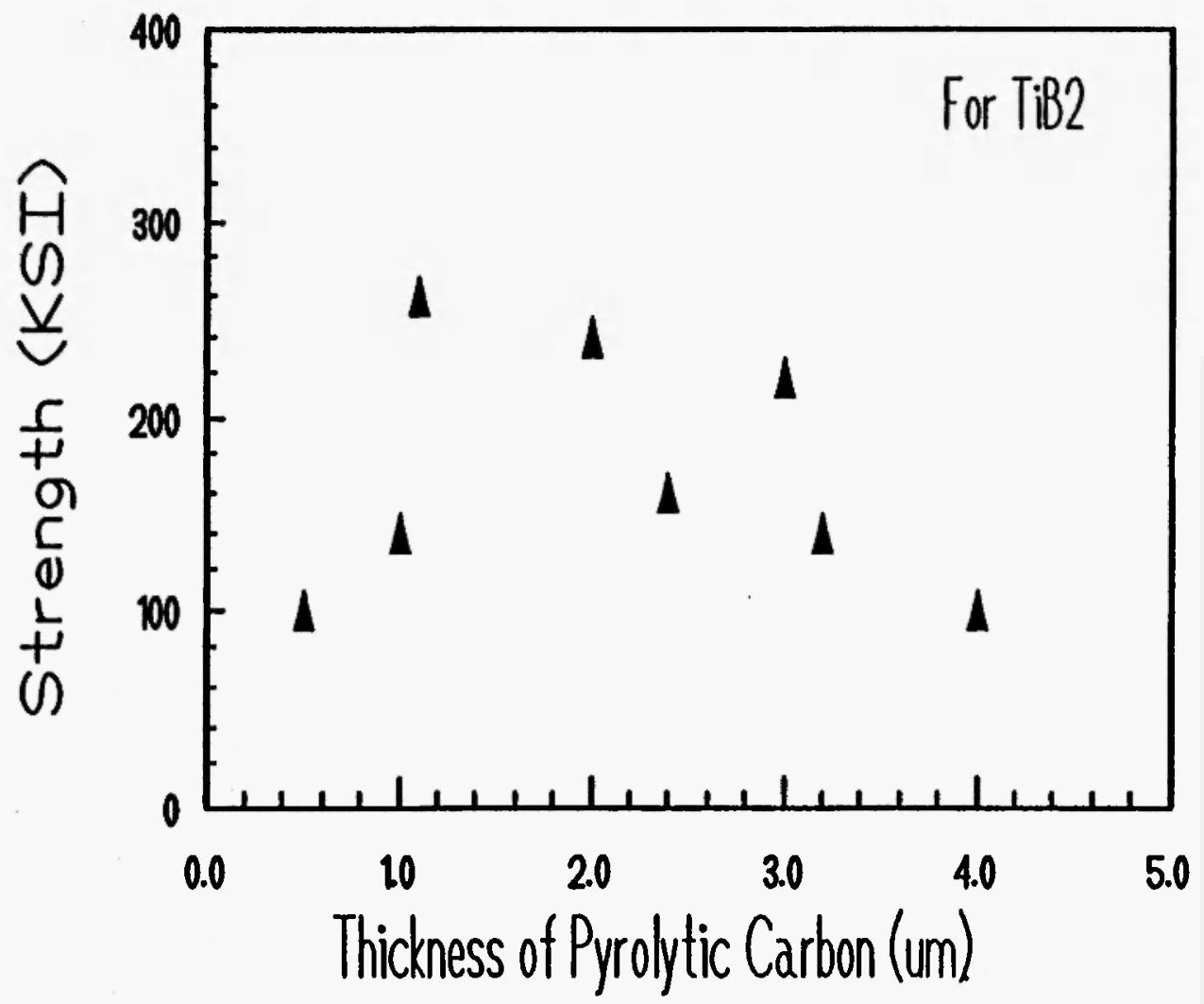

Fig. 5: Variation of strength with pyrolytic carbondeposit. 


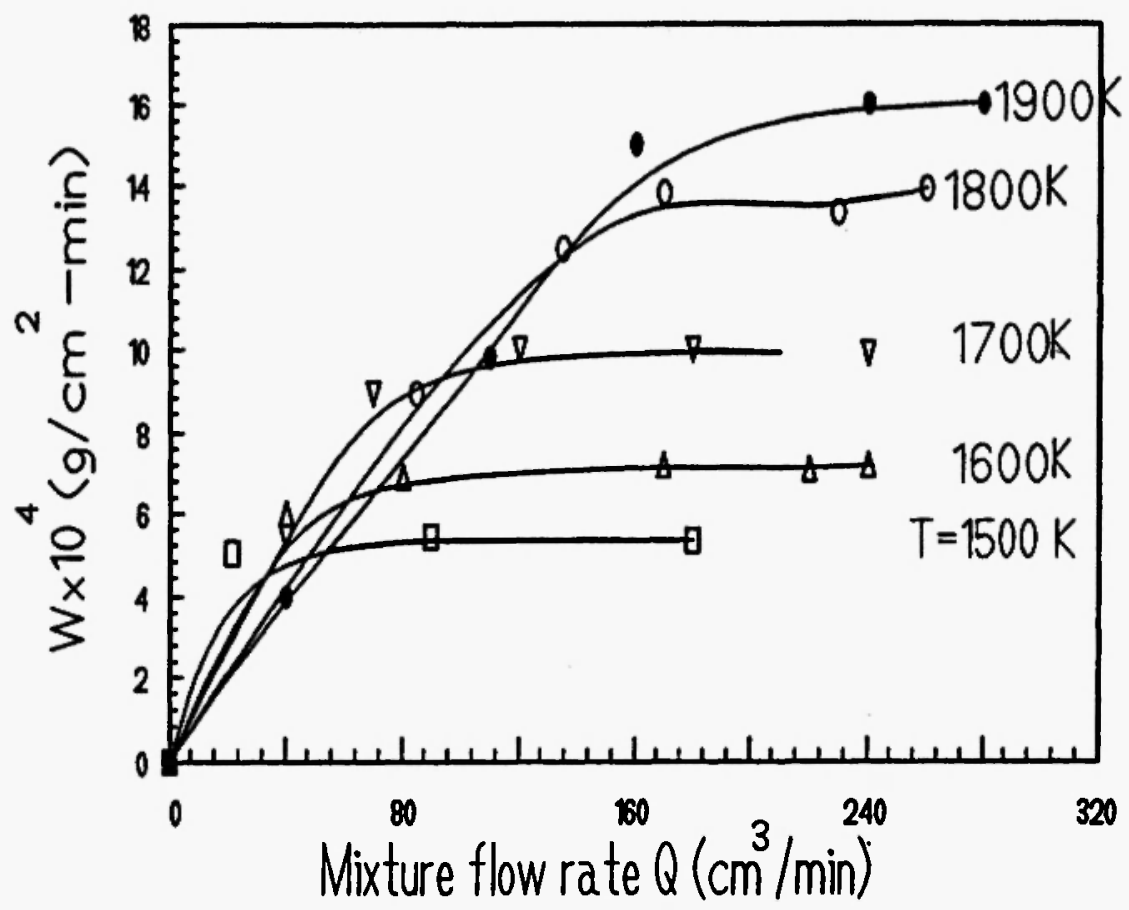

Fig. 6: Variation of deposition rate of titanium diboride with volume rate of flow of reagents.

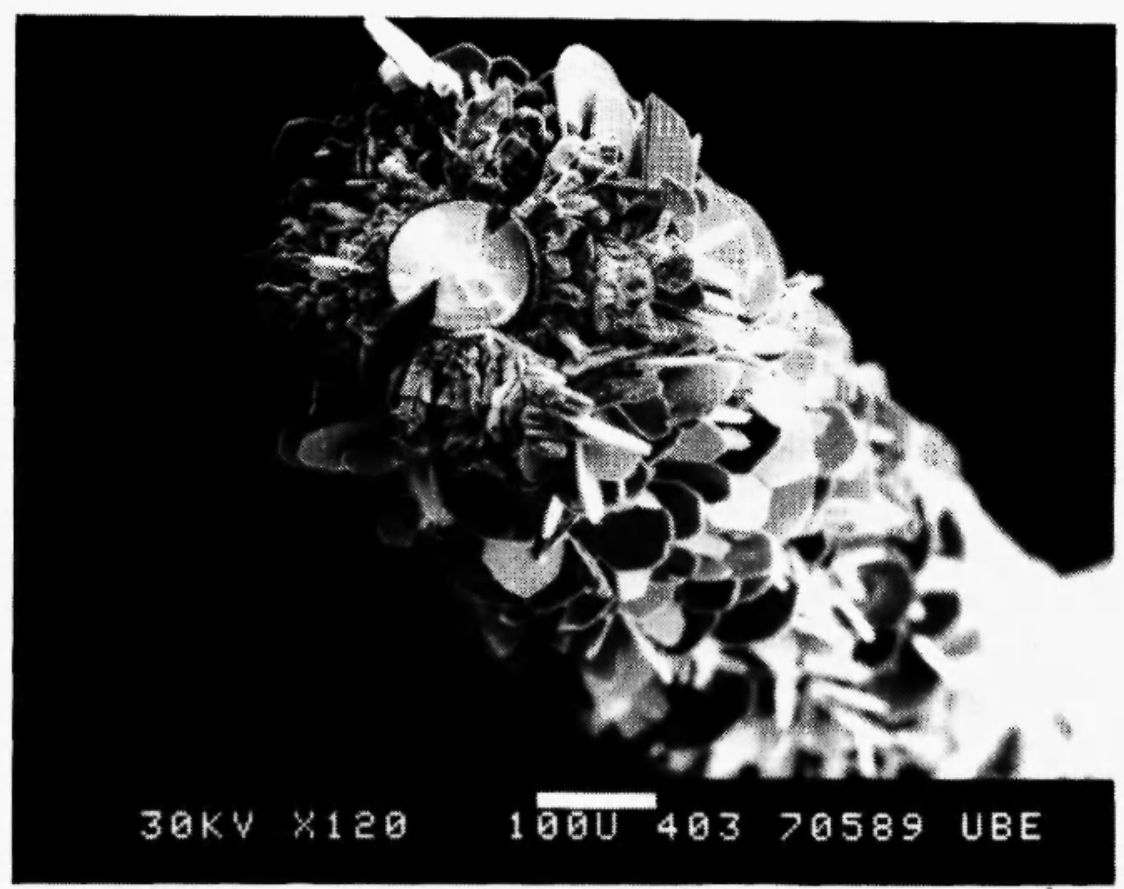

Fig. 7: $\mathrm{TiB}_{2}$ deposited at high temperature. 
TABLE 1

PROPERTIES OF FABRICATED FIBERS

\begin{tabular}{cccccccc}
\hline \hline Fiber & $\begin{array}{c}\text { M.P. } \\
{ }^{\circ} \mathrm{C}\end{array}$ & $\begin{array}{c}\text { Temp. of } \\
\text { Deposition } \\
{ }^{\circ} \mathrm{C}\end{array}$ & $\begin{array}{c}\text { Thermal } \\
\text { Expansion } \\
\times 10^{6} /{ }^{\circ} \mathrm{C}\end{array}$ & $\begin{array}{c}\text { Tensile } \\
\text { Strength } \\
\text { KSI }\end{array}$ & $\begin{array}{c}\text { Modulus } \\
\text { MSI }\end{array}$ & $\begin{array}{c}\text { Oxidation } \\
\text { Resistance }\end{array}$ & $\begin{array}{c}\text { Free } \\
\text { Carbon }\end{array}$ \\
\hline $\mathrm{TiC}$ & 3180 & 1400 & 7.6 & $200-300$ & $25-35$ & excellent & $<\%$ \\
$\mathrm{~B}_{4} \mathrm{C}$ & 2450 & 1300 & 5.0 & $300-400$ & $25-35$ & poor & $<2 \%$ \\
$\mathrm{TiB}_{2}$ & 2980 & 1000 & 7.9 & $200-300$ & $20-30$ & moderate & - \\
$\mathrm{B}$ & 2000 & 1000 & - & $400-500$ & $30-50$ & poor & - \\
\hline
\end{tabular}

matched almost with the literature values $190-200 \mathrm{KSI}$ (tensile strength), 50 MSI (modulus). The detailed results are shown in Table 1.

Fig. 8 clearly shows the different layers incorporated in the fiber. These fibers are more flexible than samples produced without the intermediate layer. Experimental conditions make it possible to protect the core completely or partially by manipulating temperature, residence time, concentrations of the secondary layer, and precursor concentration. Further steps have been taken to manufacture this fiber in continuous length.

$\mathrm{TiC}$ and $\mathrm{B}_{4} \mathrm{C}$ were also prepared by CVD. These fibers were obtained by decomposition of the corresponding halides with a hydrogen and carbon source.

\subsection{Boron Carbide and Titanium Carbide Fibers (See Figs. 9 and 10)}

The CVD process of $\mathrm{B}_{4} \mathrm{C}$ is carried out on a carbon core by reducing $\mathrm{BCl}_{3}$ and $\mathrm{CH}_{4} / \mathrm{CCl}_{4}$ with hydrogen in the temperature range $1000-1500^{\circ} \mathrm{C}$. The concentration of $\mathrm{BCl}_{3}$ and hydrocarbon $\left(\mathrm{CH}_{4} / \mathrm{CCl}_{4}\right)$ and hydrogen was varied in our experiments. The nucleation of excess of carbon was observed when $\mathrm{CH}_{4}$ was used as a precursor. This nucleation of carbon within the deposit is catalyzed by $\mathrm{BCl}_{3}$ as reported earlier $/ 14 /$. This process leads to local separation of $\mathrm{B}_{4} \mathrm{C}$ and carbon deposition. This intergranular carbon deposition exhibits a very low Young modulus and enables elastic strains of the whole deposit without plastic deformation. The problem of low modulus was partially overcome by using $\mathrm{CCl}_{4}$ as the carbon source. The optimum reactant concentration expressed in terms of $\mathrm{CI}$ to $\mathrm{H}$ ratio was found to be $1: 5$ at $1300^{\circ} \mathrm{C}$. An excess of hydrogen increases the conversion per pass of $\mathrm{BCl}_{3}$ and reaches the maximum at around $0.002 \mathrm{~m}^{3} / \mathrm{sec}$ (total gas flow rate). Our best deposit contained less than $2 \%$ of free carbon. Higher temperatures gave many side products $\left(\mathrm{BHCl}_{2}, \mathrm{BCl}_{2}\right.$, and $\left.\mathrm{BCl} / 15 /\right)$. The results are given in Table 1. Our fiber has tensile strength of approximately 300-400 KSI with a modus of approximately $35 \mathrm{MSI}$. The fiber contained less than $2 \%$ of free carbon.

Titanium carbide deposition was carried out by reducing $\mathrm{TiCl}_{4}+\mathrm{CCl}_{4}$ with hydrogen in the temperature range $1300-1500^{\circ} \mathrm{C}$. The optimum conditions were: chlorine to hydrogen ratio 1:7 with a flow rate of $0.0015 \mathrm{~m}^{3} / \mathrm{sec}$ (at $1400^{\circ} \mathrm{C}$ ), and the residence time in the reactor is $3 \mathrm{~min}$. Here we are faced with a severe problem of heterogeneous nucleation and simultaneous deposition of carbon and TiC. In the $\mathrm{CH}_{4} / \mathrm{TiCl}_{4}$ gas mixture the $\mathrm{TiC}$ nucleation is never inhibited if an excess of $\mathrm{TiCl}_{4}$ is used. Carbon core strength (fiber strength) decreases by coating. This decrease is due to the diffusion of carbon from the core substrate to the surface because of the inhibited deposition of carbon from the gaseous phase. Initial analysis showed that the best result for the deposition process can be obtained with a carbon to titanium ratio $\approx 3$. Our fibers showed a tensile strength of approximately $200-300 \mathrm{KSI}$ with a modulus of 35 MSI. Free carbon in the mixture is less than $5 \%$. Results are shown in Table 1.

\section{SUMMARY}

Titanium diboride, titanium carbide, and boron carbide fibers were fabricated. They had moderate to excellent 

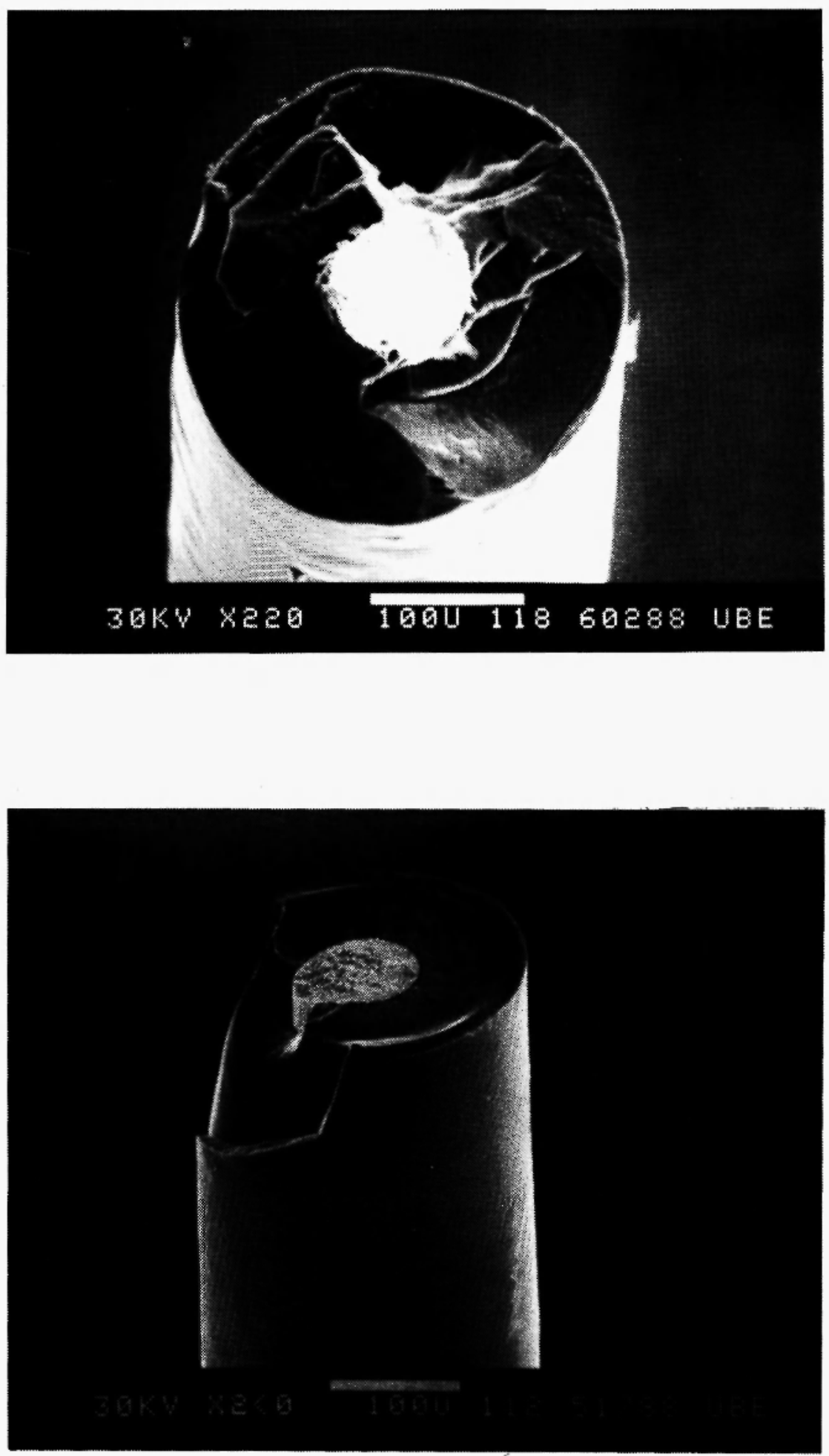

Fig. 8: $\mathrm{TiB}_{2}$ with intermediate layer of carbon. 

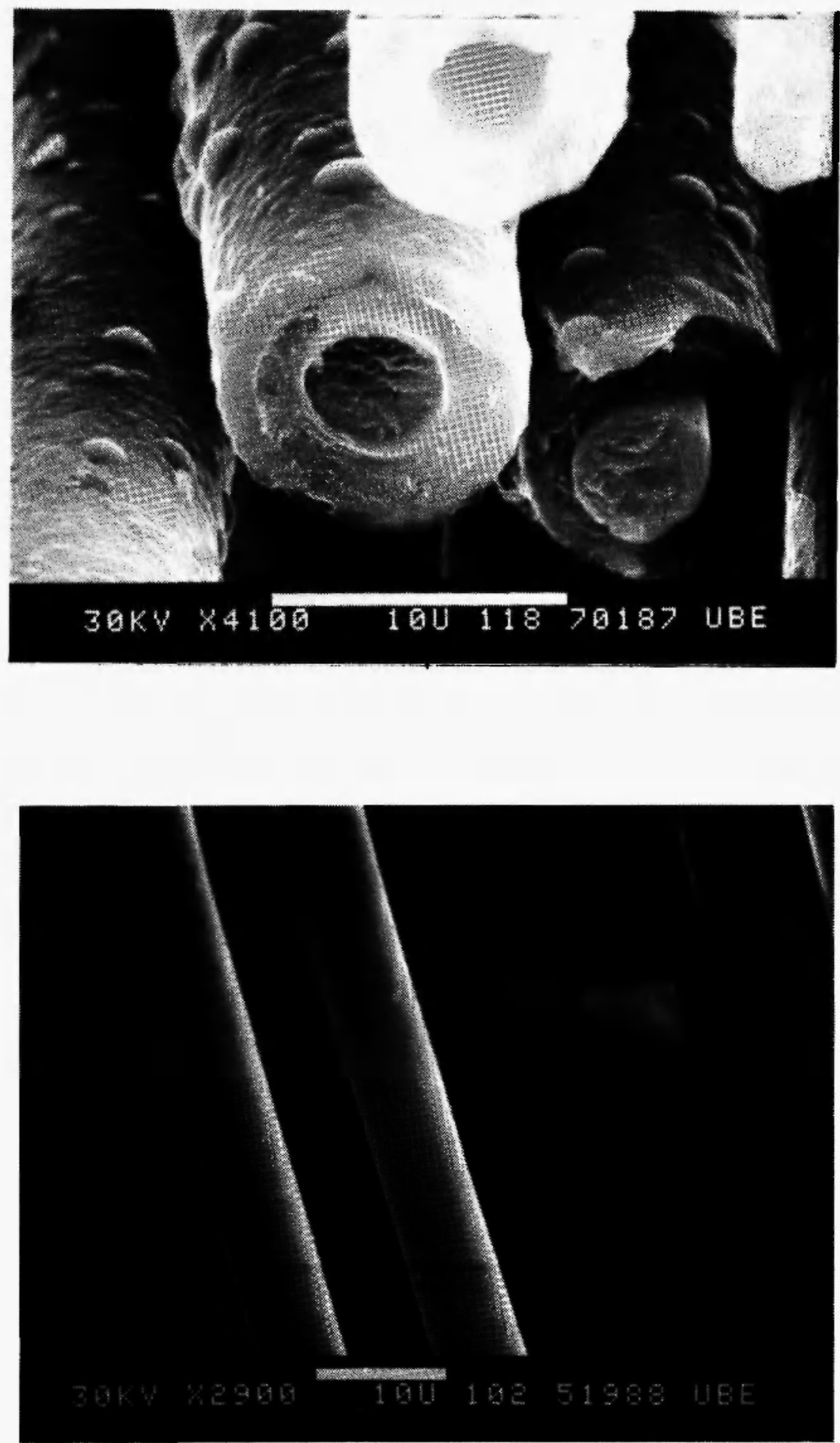

Fig. 9: TiC fibers on carbon core. (a) Direct reaction of $\mathrm{TiCl}_{4}$ with $\mathrm{H}: \mathrm{Cl}=5$ at $1400^{\circ} \mathrm{C}$. (b) Deposition reaction at $1200^{\circ} \mathrm{C}$ with $\mathrm{C}: \mathrm{Ti}=3$ and $\mathrm{H}: \mathrm{Ci}=2.5$. 

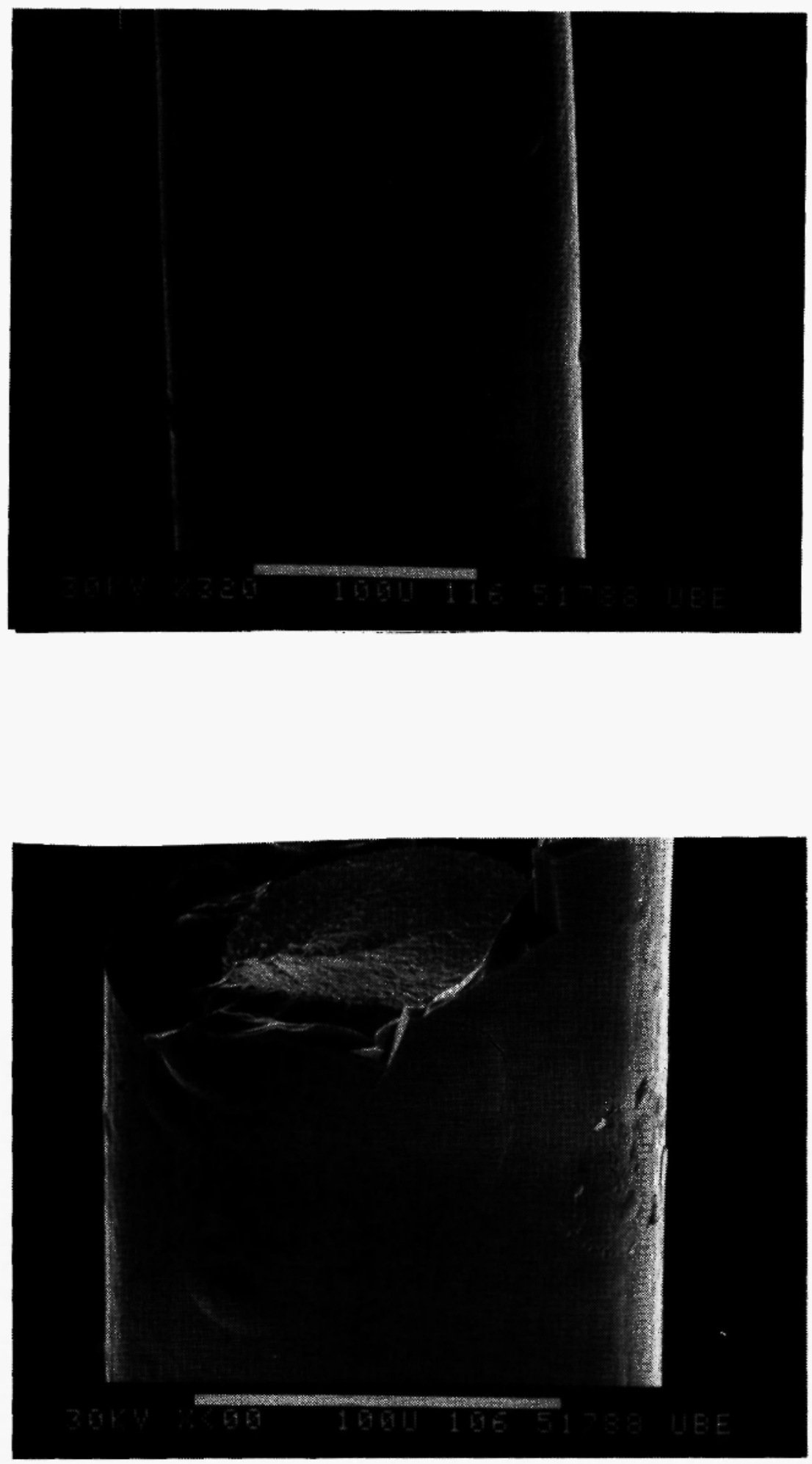

Fig. 10: $\mathrm{B}_{4} \mathrm{C}$ fibers. (a) Deposition on tungsten core at $1400^{\circ} \mathrm{C}$ with $\mathrm{B}: \mathrm{C}=2$ and $\mathrm{H}: \mathrm{Cl}=2$. (b) At the previous conditions but with $\mathrm{CH}_{4}$ as carbon source. 
quality properties. Brittleness of the fibers was minimized by incorporating a pyrolytic carbon layer. Different processing parameters were analyzed, and conditions for optimum depositions were obtained.

\section{CONCLUSIONS}

Titanium diboride fibers were fabricated up to $200 \mu \mathrm{m}$ in diameter having improved properties due to the presence of a pyrolitic carbon layer between the fiber substrate and the titanium diboride. Optimum conditions for titanium diboride deposition are $1350^{\circ} \mathrm{C}$, residence time of the fiber $=3 \mathrm{~min} . \mathrm{H}: \mathrm{Cl}>7, \mathrm{Ti}: \mathrm{B}>3$. Residence time of reacting gas $=14 \mathrm{sec}$. $\mathrm{TiC}$ and $\mathrm{B}_{4} \mathrm{C}$ fibers synthesized in our laboratory showed the required potential to apply in intermetallic reinforcement.

\section{ACKNOWLEDGEMENT}

The work described here is supported by NASA. (NAG-3897 Coordinator Dr. Petrasek)

\section{REFERENCES}

1. D.D. Edie, Int. Fiber J., 2, 6 (1987).

2. D.D. Edie and M.G. Dunham, CEEJ, 21, 186 (1987).

3. D.W. Richardson, Modem Ceramic Engineering, p. 83, Marcel Dekker, New York (1984).

4. I.E. Campbell, C.F. Fowell, D.H. Nowicki and B.W. Gonser, J. (and Trans.) Electrochem. Soc., 96, 319 (1949).

5. S.M. Johnson, R.D. Brittain and R.H. Lamoreaux, Paper presented at 172nd meeting of the Elect. Chem. Soc., Honolulu, Hawaii (1987).

6. J.J. Brennan and K.L. Prewo, J. Mat. Sci., 17, 2372 (1982).

7. D. Gloge, Bell Syst. Tech. J., 54, 245 (1975).

8. W.B. Gardner, Bell. Syst. Techn. J., 54, 457 (1975).

9. K.Z. Moers, Anorg. Allgem. Chem., 198, 243 (1931).

10. R.E. Gannon, R.C. Folweiler and J. Vasilos, Am. Ceram. Soc., 46, 469 (1963).

11. V.S. Revankar and V. Hlavacek, High Temp. Mat. \& Proc., in press.

12. E. Randich and T.M. Gerlach, Chemtech, 102 (1983).

13. J. Schlichting, Powder Metall. Int, 3, 141 (1980).

14. K. Brennfleck, E. Fitzer, G. Schoch and M. Dietrich, Proc. 9th Int. Conf. on CVD, 649 (1984).

15. R. Naslain, R. Thebault, J., P. Hagenmuller and C. Bernard. J. Less Common Metals, 67, 85 (1979). 